17. ПНД Ф Т 14.1:2:4.19-2013. Биологические методы контроля. Методика определения токсичности питьевых, грунтовых, поверхностных и сточных вод, растворов химических веществ по измерению показателей всхожести, средней длины и среднего сухого веса проростков семян кресс-салата (Lepidium sativum).
18. Урбах В.Ю. Биометрические методы (статистическая обработка опытных данных в биологии, сельском хозяйстве и медицине). М.: Наука, 1964. $415 \mathrm{c}$.

Публикация подготовлена в рамках выполнения государственного задания № 5.12863.2018/8.9.

\title{
WASTEWATER PRODUCTION OF ETHYLENEDIAMINE AND THE ASSESSMENT OF THEIR TOXICITY BY PHYTOTESTING
}

(C) 2019

Bykovsky Nikolai Alekseevich, candidate of technical sciences, associate professor of Automated and Information Systems Department

Kantor Evgeny Abramovich, doctor of chemical sciences, professor of Physics Department

Puchkova Lyudmila Nikolaevna, candidate of technical sciences,

associate professor of General Chemical Technology Department

Fanakova Nadezhda Nikolaevna, candidate of technical sciences, associate professor of Equipment for Petrochemical Plants Department

Fanakov Vadim Stanislavovich, master student of General Chemical Technology Department Ufa State Petroleum Technological University (Sterlitamak Branch)

(Sterlitamak, Republic of Bashkortostan, Russian Federation)

Abstract. This paper discusses occurrence of toxic wastewater from the production of ethylenediamine by aminating 1,2-dichloroethane with ammonia. It is shown that wastewater from ethylenediamine production is formed at the stages of evaporation of ethylenediamine dihydrochloride and rectification of a mixture of amines obtained as a result of evaporation. In the first case, the wastewater contains a saturated $\mathrm{NaCl}$ solution with a content of $1 \div 2 \%$ polyethylene polyamines, and in the second case, the drain contains a solution containing about $1 \%$ of ethylenediamine and about $2 \%$ of ammonia. To study the toxicity of these wastewater, watercress of Zabava and Krupnolistovoy varieties were used. The assessment of toxic properties of wastewater was carried out according to such values as seed germination, the average length of seedlings and the dry weight of seedlings. It is revealed that the studied drains have an acute toxic effect on the watercress of both varieties. It is shown that the regression equations obtained for the dry weight of seedlings and seed germination, in contrast to the length of the seedlings, do not adequately describe the experimental results and cannot be used to determine the safe multiplicity of breeding. The safe multiplicity of breeding, calculated using the average length of seedlings, ranges from 489,1 to 892,9 for various drains and watercress varieties. It is shown that the most toxic is the runoff containing a saturated $\mathrm{NaCl}$ solution with a content of $1 \div 2 \%$ of polyethylene polyamines Zabava is the most sensitive to the degree of toxicity of runoff.

Keywords: ethylene diamine production; wastewater; ammonia; polyethylene polyamines; salt; toxicity; watercress varieties Zabava and Krupnolistovoy; seed germination; dry weight of seedlings; average length of seedlings; correlation coefficients; regression equations; safe multiplicity of breeding.

УДК $504.732+581.553$

DOI 10.24411/2309-4370-2019-11103

Статья поступила в редакцию 15.01.2019

\section{ОСОБЕННОСТИ ПРОСТРАНСТВЕННО-ОНТОГЕНЕТИЧЕСКОЙ СТРУКТУРЫ ЦЕНОПОПУЛЯЦИЙ КОВЫЛЯ КОРЖИНСКОГО (STIPA KORSHINSKYI ROSHEV., POACEAE)}

(C) 2019

\author{
Зенкина Татьяна Евгеньевна, кандидат биологических наук, \\ начальник отдела экологии; старший преподаватель кафедры биологии \\ Волгограднефтепроект (г. Волгоград, Российская Федерация); \\ Волгоградский государственный университет (г. Волгоград, Российская Федерация) \\ Ильина Валентина Николаевна, кандидат биологических наук, \\ доцент кафедры биологии, экологии и методики обучения \\ Самарский государственный соичально-педагогический университет (г. Самара, Российская Федерация)
}

\footnotetext{
Аннотация. Математические методы анализа пространственно-онтогенетической структуры ценопопуляций редких видов растений позволяют выявить особенности организации отдельных популяций растений и фитоценозов в целом. Изучены особенности популяционной структуры ковыля Коржинского (Stipa korshinskyi Roshev., Роасеае) в Самарском Высоком Заволжье (Серноводный шихан, Сергиевский район, Самарская область). Пространственное расположение и возрастные состояния особей определены согласно традиционным популяционно-онтогенетическим методам. Особенности размещения особей S. korshinskyi с учетом их возрастного состояния определены с использованием современных математических методов. С помощью ядерной функции выявлено, что плотность особей ковыля в описываемой ценопопуляции варьировала в пределах 1-3 особи на $1 \mathrm{~m}^{2}$. Анализ интенсивности расположения особей ковыля в ценопопуляции методом квадратов показал наличие уплотненных и разреженных участков. Графическая интерпретация функции Рипли показала, что в изученной ценопопуляции растения распределены случайным образом. С помощью карты распределения доминирующих возрастных состояний отмечено, что генеративные растения находи-
} 
лись ближе к периферии участка. Графическая интерпретация кросс-функции Рипли показала, что молодые и зрелые растения S. korshinskyi в ценопопуляции размещаются случайным образом. По-видимому, в целом случайный характер размещения особей свойственен для ценопопуляций S. korshinskyi, испытывающих в составе фитоценозов значительную антропогенную нагрузку.

Ключевые слова: Stipa korshinskyi Roshev.; ценопопуляция; пространственная структура; возрастное состояние; функция Рипли; кросс-функция Рипли; локальная плотность; интенсивность размещения особей; случайное размещение; Самарская область; Серноводный шихан.

\section{Введение}

Важным аспектом биоэкологического мониторинга природных комплексов является изучение структурных и функциональных особенностей ценопопуляций представителей региональных флор, входящих в состав растительных сообществ как зонального, так и азонального характера. Анализ полученных результатов должен быть весьма разносторонним для выявления особенностей и закономерностей организации популяций модельных видов.

Среди изучаемых представителей флоры степей юго-востока Европейской части России следует назвать ковыль Коржинского (Stipa korshinskyi Roshev., Poaceae) (рис. 1). На территории Самарской области вид произрастает вблизи западной границы ареала. Он включен в список охраняемых представителей
Самарской области с природоохранным статусом 3 редкий вид [1]. Находится под охраной и в других регионах - в Республике Татарстан [2] и Ульяновской области [3].

\section{Материалы и методы исследования}

В Самарском Высоком Заволжье нами исследованы особенности размещения особей S. korshinskyi с учетом их возрастного состояния. Выявлены особенности организации ценопопуляции вида на Серноводном шихане (памятник природы регионального значения, расположенный в Сергиевском районе Самарской области) (рис. 2). Здесь S. korshinskyi является содоминантом в составе сообщества Artemisia salsoloides Willd. + Hedysarum grandiflorum Pall. Stipa korshinskyi Roshev.

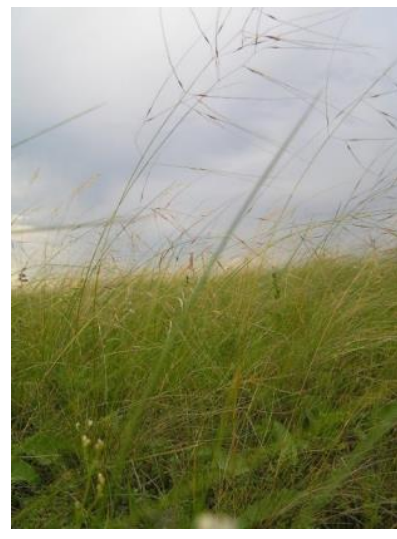

Рисунок 1 - Ковыль Коржинского (Stipa korshinskyi Roshev., Poaceae) (фотография авторов)

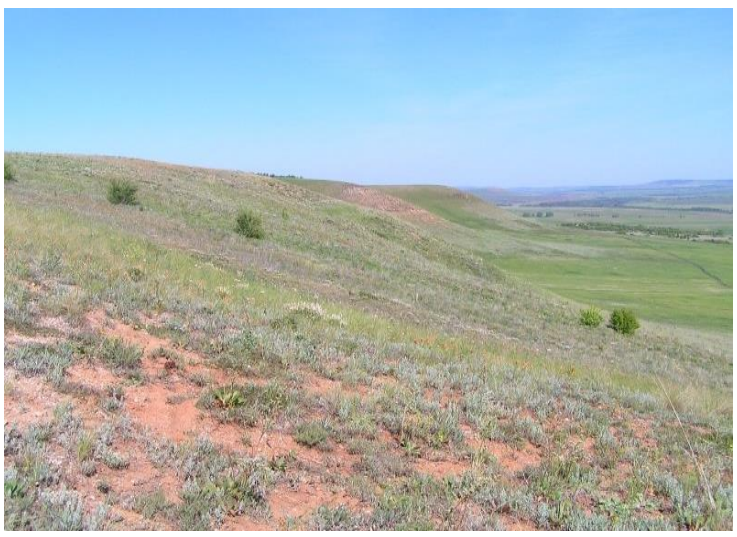

Рисунок 2 - Петрофитные степи на склонах Серноводного шихана (памятник природы регионального значения, Сергиевский район Самарской области) (фотография авторов)
Освещенные в статье результаты дополняют серию публикаций авторов, в которых описаны особенности пространственно-онтогенетической структуры ценопопуляций редких видов растений флоры Самарской области [4].

Анализ пространственно-онтогенетической структуры ценопопуляций проведен на основе оригинальных данных, полученных в ходе изучения ценотических популяций традиционными методами [5-7]. Оценка пространственного расположения особей выполнена с использованием современных математических методов [8-10]. Осуществлены расчет $K(r)$ функции Рипли $[11 ; 12]$ и составление карт локальной плотности при помощи метода бегущего (скользящего) окна (moving window) [13], основанного на ядерных функциях kernel (kernel function) [14; 15]. Для удобства анализа полученный результат представлен графически в виде функции $L(r)-r$, где $L(r)=\sqrt{ } K(r) / \pi[16]$. Анализ закономерностей пространственного расположения двух классов особей использована кросс-функция Рипли. Вычисления проведены в среде R (version 3.3.2) с помощью пакета SPATSTAT [17]. Для оценки значимости отклонений $L(r)$ от $L_{C S R}(r)$ использован метод симуляций МонтеКарло [18]. Интенсивность расположения особей оценивалась методом квадратов [19; 20].
Результаты и их обсуждение

С помощью ядерной функции выявлено, что плотность особей ковыля в описываемой ценопопуляции варьировала в пределах 1-3 особи на $1 \mathrm{~m}^{2}$. Всего на стационарном участке было отмечено 25 особей. Практически половину составили генеративные растения $\left(g_{1}, g_{2}, g_{3}\right)-13$ особей. Прегенеративная группа особей была представлена только виргинильными растениями (v) - 12 особей (рис. 3 ).

Анализ интенсивности расположения особей ковыля в ценопопуляции методом квадратов показал наличие уплотненных и разреженных участков. Согласно выполненным расчетам оптимальное количество квадратов, на которое разбивается исследуемая территория размером $25 \mathrm{M}^{2}$, составляет 16 шт. (сетка $4 \times 4$ ), с размером стороны 1,25 м $[19 ; 20]$. Более плотное размещение особей $(2,6)$ было отмечено на двух участках. Разреженность характеризовалась значением интенсивности менее единицы, также выделялись участки с полным отсутствием данного вида (рис. 4).

При оценке пространственного размещения всех особей ковыля на стационарном участке без выделения возрастных состояний использовалась функция Рипли $[11 ; 12]$. Графическая интерпретация функции показала, что в изученной ценопопуляции растения распределены случайным образом (рис. 5). 


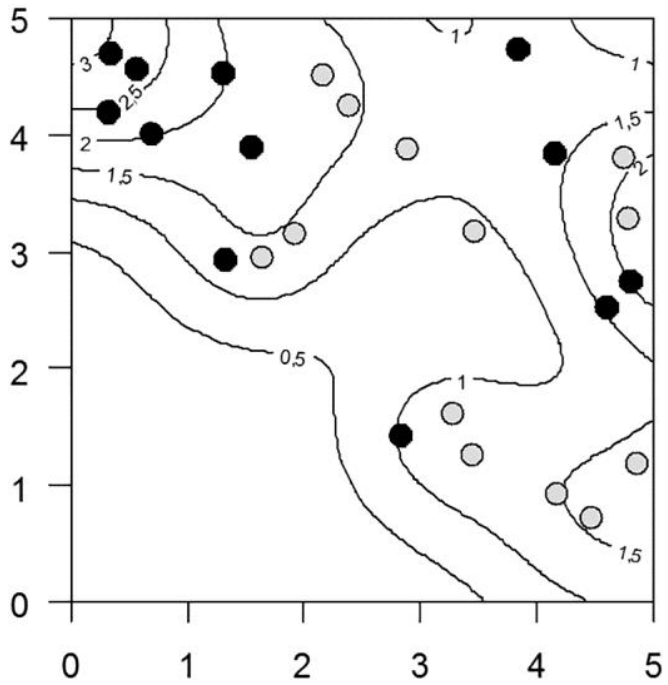

Рисунок 3 - Карта-схема локальной плотности ЦП Stipa korshinskyi (чёрные символы - генеративные особи, серые символы - прегенеративные особи)

С помощью карты распределения доминирующих возрастных состояний было отмечено наличие тенденции в размещении особей S. korshinskyi разных возрастных групп [20]. Так, генеративные растения находились ближе к периферии (светлые участки на карте), темные участки соответствовали местам наиболее вероятной встречи прегенеративных особей (рис. 6).

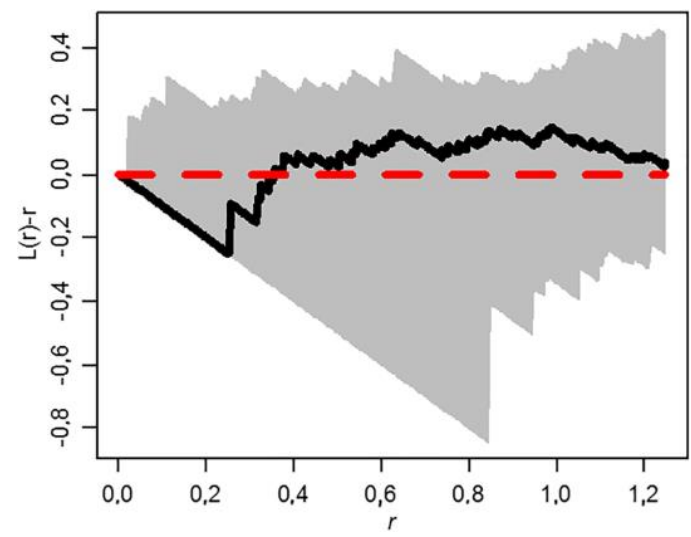

Рисунок 5 - Поведение функции Рипли для особей S. korshinskyi

(без учета возрастных состояний)

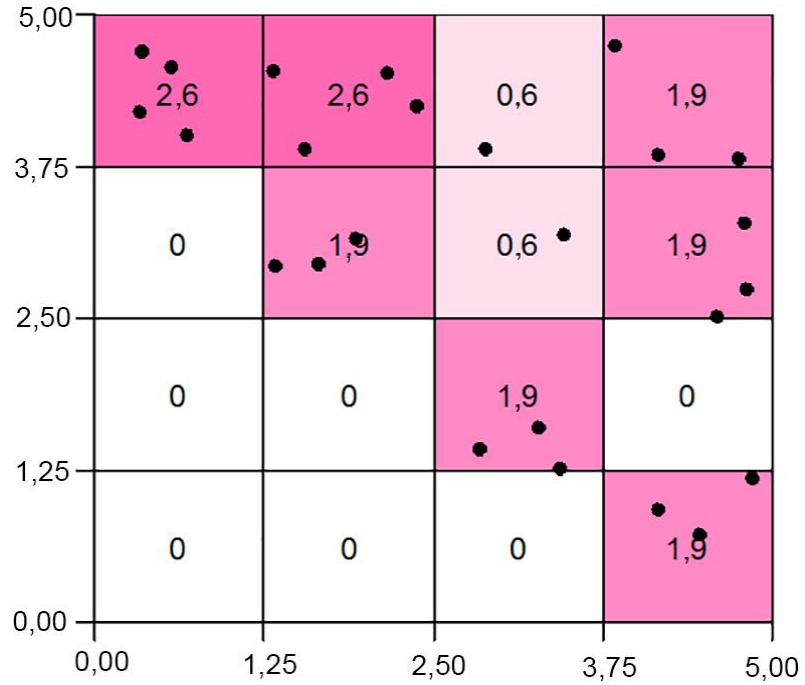

Рисунок 4 - Оценка интенсивности расположения особей Stipa korshinskyi

Также кросс-функция Рипли позволила выявить дополнительные особенности размещения особей прегенеративной и генеративной возрастных групп S. korshinskyi. Графическая интерпретация показала, что молодые и зрелые растения в ценопопуляции размещаются случайным образом, расположение их по отношению друг к другу также носит случайный характер (рис. 7).

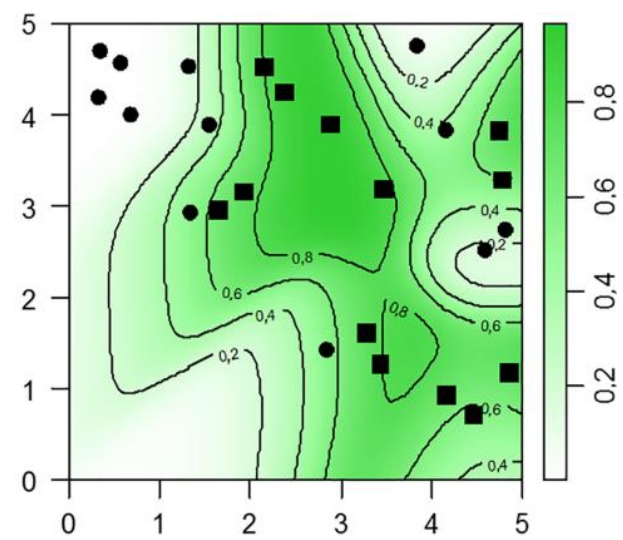

Рисунок 6 - Карта распределения возрастных состояний в ЦП S. korshinskyi (черные кружки - генеративные особи, черные квадраты - прегенеративные особи)

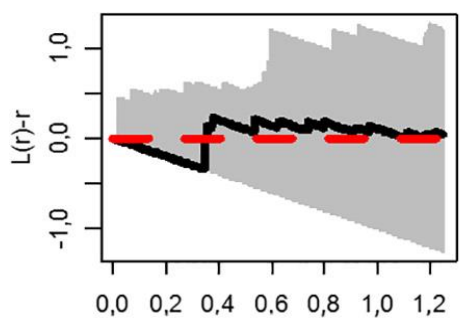

A

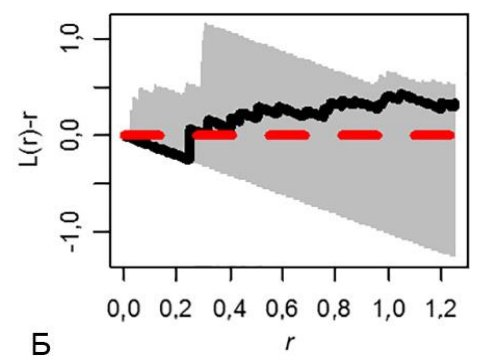

5

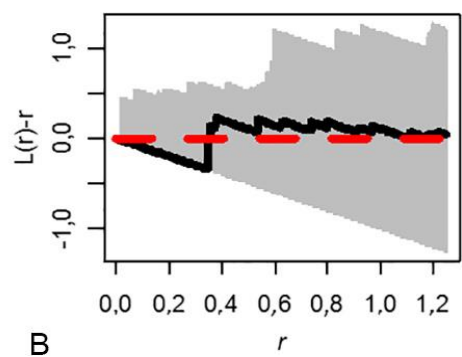

$\mathrm{B}$

Рисунок 7 - Типы поведения кросс-функции Рипли в ЦП

( $A$ - прегенеративные особи, 5 - генеративные особи,

$B$ - взаимное размещение генеративных и прегенеративных особей

Выводы

Выявлено, что на численность и пространственный узор ЦП редких видов растений на территории памятника природы регионального значения «Серноводный шихан», в том числе у S. korshinskyi, в зна- чительной мере влияет антропогенная нагрузка. Катастрофическим фактором, влияние которого на почвенно-растительный покров памятника природы отмечается ежегодно, следует назвать пирогенный. Кроме того, природный комплекс испытывает рекре- 
ационную (замусоривание, вытаптывание, развитие дорожной и тропиночной сети) и пасквальную нагрузку, что отмечалось и ранее [21-23]. Постоянное воздействие на растительные комплексы при выпасе и палах в значительной мере обусловливают случайный характер расположения особей S. korshinskyi и других видов растений.

\section{Список литературы:}

1. Красная книга Самарской области. Т. І. Редкие виды растений и грибов / под ред. С.А. Сенатора, С.В. Саксонова. Самара, 2017. 384 с.

2. Красная книга Республики Татарстан (животные, растения, грибы). Казань: Изд-во «Идел-Пресс», 2016. $760 \mathrm{c}$.

3. Красная книга Ульяновской области / под науч. ред. Е.А. Артемьевой, А.В. Масленникова, М.В. Корепова. М.: Изд-во «Буки Веди», 2015. 550 с.

4. Зенкина Т.Е., Ильина В.Н. Характеристика структуры ценопопуляций копеечника крупноцветкового (Hedysarum grandiflorum Pall., Fabaceae) с использованием методов пространственной статистики // Самарская Лука: проблемы региональной и глобальной экологии. 2019. Т. 28, № 1. С. 56-63.

5. Работнов Т.А. Жизненный цикл многолетних травянистых растений в луговых ценозах // Труды БИН АН СССР. Сер. 3. Геоботаника. М.: АН СССР, 1950. Вып. 6. С. 7-204.

6. Уранов А.А. Возрастной спектр фитоценопопуляций как функция времени и энергетических волновых процессов // Биол. науки. 1975. № 2. С. 7-34.

7. Жукова Л.А. Популяционная жизнь луговых растений. Йошкар-Ола: ЛАНАР, 1995. 224 с.

8. Фардеева М.Б., Исламова Г.Р. К изучению пространственной структуры черники (Vaccinium myrtillus L.) // Окружающая среда и устойчивое развитие регионов: новые методы и технологии исследований: труды всерос. конф. с междунар. уч. Казань, 2009. C. $307-312$.

9. Фардеева М.Б., Чижикова Н.А., Бирючевская Н.В., Рогова Т.В., Савельев А.А. Математические подходы к анализу пространственно-возрастной структуры популяций дерновинных видов трав // Экология. 2009. № 4. С. 249-257.

10. Фардеева М.Б., Чижикова Н.А., Красильникова О.В. Многолетняя динамика онтогенетической и пространственной структуры ценопопуляций Cypripedium calceolus L. // Ученые записки Казанского гос. ун-та. Серия: Естеств. науки. 2010. Т. 152, кн. 3. C. $159-173$.

\section{FEATURES OF THE SPATIAL AND ONTOGENETIC STRUCTURE OF THE STIPA KORSHINSKYI ROSHEV. (POACEAE) CENOPOPULATION}

(C) 2019

Zenkina Tatyana Evgenievna, candidate of biological sciences, head of Ecology Department; senior lecturer of Biology Department Volgogradnefteproekt (Volgograd, Russian Federation);

Volgograd State University (Volgograd, Russian Federation)

Ilina Valentina Nikolaevna, candidate of biological sciences, associate professor of Chair of Biology, Ecology and Methods of Teaching Samara State University of Social Sciences and Education (Samara, Russian Federation)

Abstract. Mathematical methods of analysis of the spatial and ontogenetic structure of rare plant species cenopopulations allow us to reveal organization features of individual plant populations and phytocenoses as a whole.
11. Ripley B.D. The second-order analysis of stationary point processes // Journal of Applied Probability. the Royal Statistical Society. Ser. B. 1977. № 39.

13. Bailey T.C., Gatrell A. Interactive spatial data analysis. Harlow, England: Longman Scientific \& Tech1995. $413 \mathrm{p}$ \& Sons Ltd, 1992. 384 p.

16. Besag J. Contribution to the discussion of Dr Ripley's paper // Journal of the Royal Statistical Society. B. 1977. № 39. P. 193-195. al Software. 2005. Vol. 12 (6). P. 1-42.

PJ Simple Monte Carlo 19. Савельев А.А., Мухарамова С.С., Чижикова Н.А., Пилюгин А.Г. Теория пространственных то-

20. Шитиков В.К., Розенберг Г.С. Рандомизация и сандра, 2014. 314 с. арская Лука. 2003. № 13. С. 294-310.

Митрошенкова А.Е., Ильина В.Н., Ильина Н.С., 2012 г., Самара. Самара: ПГСГА, 2012. С. 169-174. (Высокое Заволжье) // Фиторазнообразие Восточной Европы. 2013. Т. 7, № 2. С. 28-40.
6. № 13. P. 255-266. 
The authors study the features of the Stipa korshinskyi Roshev. (Poaceae) population structure in the Samara High Trans-Volga Region (Sernovodny Shihan, Sergievsky District, Samara Region). Spatial location and age conditions of individuals are determined according to traditional population-ontogenetic methods. The characteristics of the distribution of individuals of S. korshinskyi, taking into account their age, are determined using modern mathematical methods. With the help of the nuclear function, it was revealed that the density of the feather grass individuals in the described cenopopulation varied in the range of 1-3 individuals per $1 \mathrm{~m}^{2}$. Analysis of $S$. korshinskyi individuals location intensity in coenopulation using the square method showed the presence of compacted and rarefied sections. The graphical interpretation of the Ripley function showed that in the studied cenopopulation the plants are randomly distributed. Using the distribution map of the dominant age states it was noted that the generative plants were closer to the periphery of the site. Graphic interpretation of Ripley's cross-function showed that young and mature plants are placed randomly in cenopopulation. Apparently, on the whole, the random nature of the individuals distribution is characteristic of $S$. korshinskyi cenopopulations experiencing a significant anthropogenic load in the composition of the phytocenoses.

Keywords: Stipa korshinskyi Roshev.; cenopopulation; spatial structure; age condition; Ripley function; Ripley's cross function; local density; intensity of individuals placement; random placement; Samara Region; Sernovodny Shihan.

\section{ПОДХОДЫ К ОЦЕНКЕ ЧИСЛЕННОСТИ НАСЕЛЕНИЯ КРЫС (RATTUS NORVEGICUS) И СНИЖЕНИЮ ИХ КОЛИЧЕСТВА В ГОРОДСКОЙ СРЕДЕ}

(C) 2019

Зорина Анастасия Александровна, кандидат биологических наук, доцент кафедры зоологии и экологии Киреева Марина Леонидовна, научный сотрудник лаборатории функциональной зоологии Петрозаводский государственный университет (г. Петрозаводск, Российская Федерация)

Аннотация. Рассмотрены традиционные, современные и перспективные (на стадии разработки и апробации) методы учета городских серых крыс и мероприятия по снижению их численности. Анализ способов оценки населения грызунов показал отсутствие универсальной методики определения количества городских крыс, которая бы учитывала как эколого-биологические характеристики вида, так и особенности конкретной городской территории. Основная рекомендация по организации мониторинга заключается в оценке направления изменения численности городских крыс, определения трендов сокращения или увеличения их населения. Мероприятия по снижению количества пасюка на урбанизированной территории делятся на технологии уменьшения емкости среды их обитания (профилактические методы) и собственно дератизацию. Разнообразие способов дератизации и одновременное их применение недостаточно для полного истребления крыс в условиях городской среды. Высокая экологическая пластичность вида, разнообразие местообитаний, особенности жизнедеятельности самого человека (включая обеспечение безопасности людей и нецелевых групп животных) и другие факторы с низкой степенью прогноза приводят к отсутствию эффективных универсальных моделей элиминации крыс в городах России и за рубежом. С точки зрения популяционной биологии задача по сокращению численности состоит не просто в том, чтобы ее уменьшать, но в том, чтобы не допустить «взрыва»- момента, когда в размножение вступают поколения молодых крыс (для большинства регионов - это середина лета). Воздействуя на популяцию крыс дважды в год (май, июль), можно стабилизировать ее численность на относительно низком уровне. Отмечены основные сложности при стандартизации мероприятий и составлении регламента по контролю численности крыс.

Ключевые слова: аналитический обзор; Rattus norvegicus; мониторинг численности крыс; методика; емкость среды; урбанизированная территория; химические методы дератизации; физические методы дератизации; биологические методы дератизации; регламент; экологическая пластичность вида; экстраполяция данных; профилактика.

\section{Введение}

Распространение серой крысы, как синантропного вида грызунов, тесно связано с особенностями жизнедеятельности человека. Расширяя свой ареал, пасюк может жить как в естественных местообитаниях $[1 ; 2]$, так и на фермах, складах и предприятиях пищевой промышленности, а также в городской среде [2-4]. С учетом урбанизации населения экспансия крысы продолжается, а численность вида устойчиво сохраняется на высоком уровне. Экономический ущерб, приносимый грызунами народному хозяйству, огромен. Рост их численности приводит к природно-очаговым инфекционным заболеваниям человека и многих животных $[2 ; 5 ; 6]$.
Полное истребление крыс практически невозможно, а их восстановление проходит быстро за счет высокого репродуктивного потенциала [5; 7]. В настоящее время говорят о регуляции населения зверьков, точная оценка численности которой также проблематична. Основной целью управления популяцией крыс является достижение допустимого их количества, при котором риски от их жизнедеятельности оказываются минимальными для человека и среды его обитания [8; 9].

Таким образом, для оптимизации среды жизни человека в городских условиях необходимо стремиться контролировать численность серых крыс. Это означает введение системы мониторинга за размером 